\title{
HER1-Targeted ${ }^{86}$ Y-Panitumumab Possesses Superior Targeting Characteristics than ${ }^{86} \mathrm{Y}$-Cetuximab for PET Imaging of Human Malignant Mesothelioma Tumors Xenografts
}

\author{
Tapan K. Nayak*, Kayhan Garmestani, Diane E. Milenic, Kwamena E. Baidoo, Martin W. Brechbiel ${ }^{*}$
}

Radioimmune \& Inorganic Chemistry Section, Radiation Oncology Branch, National Cancer Institute, National Institute of Health, Bethesda, Maryland, United States of America

\begin{abstract}
Malignant mesothelioma (MM), a rare form of cancer is often associated with previous exposure to fibrous minerals, such as asbestos. Asbestos exposure increases HER1-activity and expression in pre-clinical models. Additionally, HER1 overexpression is observed in the majority of MM cases. In this study, the utility of HER1-targeted chimeric IgG ${ }_{1}$, cetuximab, and a human $\operatorname{lgG}_{2}$, panitumumab, radiolabeled with ${ }^{86} \mathrm{Y}$, were evaluated for PET imaging to detect MM non-invasively in vivo, and to select an antibody candidate for radioimmunotherapy (RIT).

Methods: Radioimmunoconjugates (RICs) of cetuximab and panitumumab were prepared by conjugation with $\mathrm{CHX}-\mathrm{A}^{\prime \prime}-$ DTPA followed by radiolabeling with ${ }^{86} \mathrm{Y}$. The HER1 expression of $\mathrm{NCl}-\mathrm{H} 226, \mathrm{NCl}-\mathrm{H} 2052, \mathrm{NCl}-\mathrm{H} 2452$ and MSTO-211H human mesothelioma cells was characterized by flow cytometry. In vivo biodistribution, pharmacokinetic analysis, and PET imaging were performed in tumor bearing athymic mice.

Results: In vivo studies demonstrated high HER1 tumor uptake of both RICs. Significant reduction in tumor uptake was observed in mice co-injected with excess $\mathrm{mAb}(0.1 \mathrm{mg})$, demonstrating that uptake in the tumor was receptor specific. Significant differences were observed in the in vivo characteristics of the RICs. The blood clearance $T_{1 / 2} \alpha$ of ${ }^{86} \mathrm{Y}$-cetuximab $(0.9-1.1 \mathrm{~h})$ was faster than ${ }^{86} \mathrm{Y}$-panitumumab (2.6-3.1 h). Also, the tumor area under the curve (AUC) to liver AUC ratios of ${ }^{86} \mathrm{Y}$-panitumumab were 1.5 to 2.5 times greater than ${ }^{86} \mathrm{Y}$-cetuximab as observed by the differences in PET tumor to background ratios, which could be critical when imaging orthotopic tumors and concerns regarding radiation doses to normal organs such as the liver.
\end{abstract}

Conclusion: This study demonstrates the more favorable HER1-targeting characteristics of ${ }^{86} Y$-panitumumab than ${ }^{86} Y$ cetuximab for non-invasive assessment of the HER1 status of MM by PET imaging. Due to lower liver uptake, panitumumab based immunoconjugates may fare better in therapy than corresponding cetuximab based immunoconjugates.

Citation: Nayak TK, Garmestani K, Milenic DE, Baidoo KE, Brechbiel MW (2011) HER1-Targeted ${ }^{86}$ Y-Panitumumab Possesses Superior Targeting Characteristics than ${ }^{86}$ Y-Cetuximab for PET Imaging of Human Malignant Mesothelioma Tumors Xenografts. PLoS ONE 6(3): e18198. doi:10.1371/journal.pone.0018198

Editor: Andrew Yeudall, Virginia Commonwealth University, United States of America

Received October 28, 2010; Accepted February 28, 2011; Published March 25, 2011

This is an open-access article, free of all copyright, and may be freely reproduced, distributed, transmitted, modified, built upon, or otherwise used by anyone for any lawful purpose. The work is made available under the Creative Commons CCO public domain dedication.

Funding: The Intramural Research Program of the $\mathrm{NIH}, \mathrm{NCl}$, Center for Cancer Research and the United States Department of Health and Human Services. The funders had no role in study design, data collection and analysis, decision to publish, or preparation of the manuscript.

Competing Interests: The authors have declared that no competing interests exist.

*E-mail: tapann@gmail.com (TKN); martinwb@mail.nih.gov (MWB)

\section{Introduction}

Asbestos-related deaths have increased 400 percent in the past 20 years and the number of cases continues to increase despite awareness of asbestos-related hazards [1,2]. Asbestos is a human mutagen and carcinogen, responsible for many pulmonary diseases including asbestosis, bronchogenic carcinoma, and malignant mesothelioma [2]. Malignant mesothelioma (MM) is a rare form of an aggressive and often treatment-resistant cancer [3]. Occupational exposure to asbestos is implicated in $70-80 \%$ of all MM. After initial diagnosis, MM has a median survival of 10-18 months [3,4]. Conventional therapies, such as surgery, radiotherapy, and chemotherapy, do not necessarily improve overall survival. On the other hand, tremendous advances have been made regarding understanding the molecular biology of MM.
Understanding the molecular biological features of asbestosinduced MM is of critical importance. MM cells arise from the pleura or the peritoneal cavity and produce numerous growth factors, including epidermal growth factor (EGF), platelet-derived growth factor (PDGF), and transforming growth factor $\beta$ (TGF- $\beta$ ) $[3,5,6]$. EGF is a potent mitogen for human mesothelial cells. In normal and pre-malignant animal cells of similar type, exposure to asbestos leads to autophosphorylation, increased expression of the cell surface EGF receptor (HER 1) that then appears to initiate cell signaling cascades important in asbestos-induced mitogenesis and carcinogenesis $[7,8,9]$

Recent clinical studies have also shown over-expression of HER1 in MM [10,11,12,13]. In an immunohistochemical (IHC) and molecular study with clinico-pathological correlations, a statistically significant correlation was observed between the 
expression of HER 1 by IHC and corresponding mRNA levels. Secondly, HERl mRNA levels were higher in tumor specimens than non-neoplastic pleura samples [14]. In another study comprising 71 patients, high HERl expression was detected in $74.6 \%$ of the cases; $52.1 \%$ cases were positive for HER l gene amplification and $45 \%$ of the cases had elevated serum HER 1 [10]. In that same study, elevated serum and tissue HERl was significantly associated with advanced disease stage, suggesting an important role of EGFR over-expression in mesothelioma $[10,11,12,13]$.

Based on the findings that HER1 is over-expressed in MM, HER 1-tyrosine kinase inhibitors (TKIs) such as gefinitib and erlotinib were investigated for therapy of MM patients $[15,16]$. In the study utilizing gefinitib, $97 \%$ of the patients with MM were found to have presented with disease that over-expressed HER1, the gefitinib therapy, however, was ineffective and HER 1 expression did not correlate with failure-free survival [16]. Similarly, single agent erlotinib therapy was ineffective in MM, despite high expression of HERl. The authors speculated that the activation of the ERK and phosphatidylinositol 3-kinase/Akt downstream pathways as possible resistance mechanisms to erlotinib [15].

Since the majority of MMs over-express HER1, this target might prove suitable for molecular imaging and, ultimately, targeted radionuclide therapy of MM. Targeted radionuclide therapy and radioimmunotherapy (RIT) are at the forefront of molecular cancer treatment modalities that involve the use of cancer cell targeting radiopharmaceuticals, such as radiolabeled antibodies, which selectively target certain tumor cells $[17,18] .{ }^{90} \mathrm{Y}$ is one of the very promising radionuclides used for radioimmunotherapy of hematologic malignancies and solid tumors $[19,20,21]$ Such radionuclide therapy outcomes will be independent of mutations in HER 1 or KRAS domains and therefore overcome the existing limitations of conventional HER1-targeted therapy. However, since ${ }^{90} \mathrm{Y}$ is a pure $\beta^{-}$-emitter, its biodistribution cannot be readily imaged for patient-specific dosimetry which is essential for pre-therapeutic treatment planning and accurate absorbed dose estimation in individual patients to mitigate radiation risks. ${ }^{111} \mathrm{In}$ and ${ }^{89} \mathrm{Zr}$ were used as surrogate PET radionuclides for ${ }^{90} \mathrm{Y}$, however disparities were observed in the biodistribution of these and ${ }^{90} \mathrm{Y}$ labeled antibodies [22,23]. In recent years, ${ }^{86} \mathrm{Y}$ has gained popularity as an attractive surrogate for studying ${ }^{90} \mathrm{Y}$ due to its half-life $(14.7 \mathrm{~h})$ and positron emission which allows quantitative imaging over $2-3$ days [24]. Since the chemical form is identical to ${ }^{90} \mathrm{Y},{ }^{86} \mathrm{Y}$ labeled antibodies have identical biodistribution to ${ }^{90} \mathrm{Y}$ labeled antibodies, and therefore should enable more accurate absorbed dose estimates for ${ }^{90} \mathrm{Y}$ [25]. Based on the previous experiences with ${ }^{64} \mathrm{Cu}$ (half-life $=12.7 \mathrm{~h}$ ) labeled antibodies in patients it is anticipated that between $0.18-$ $0.37 \mathrm{GBq}$ of the injected ${ }^{86} \mathrm{Y}$ labeled antibody will result in useful quantitative images up to 2-3 d after injection [26,27]. Therefore, in this study we sought to explore the utility of HER1-targeting ${ }^{86}$ Y-labeled cetuximab and panitumumab for PET imaging of MM, to assess HERl status, and as a means to select and screen subjects for HER1-targeted radioimmunotherapy (RIT) with radionuclides such as ${ }^{90} \mathrm{Y}$ for larger tumors or $\alpha$-emitting radionuclides such as ${ }^{212} \mathrm{~Pb}$ for micrometastatic disease $[28,29,30,31]$.

In the present study, the in vitro characterization of four established MM cell lines for HER1 expression is described. Also detailed are the in vivo targeting characteristics of ${ }^{86} \mathrm{Y}$-labeled panitumumab and cetuximab in three human MM tumor xenograft models in mice for potential use in risk stratification and quantitative non-invasive imaging of HER 1, and assessment of mAb uptake in MM. In addition to the development of a potential PET imaging agent, another objective of the studies described herein was the selection of a preferred antibody candidate for future RIT studies.

\section{Results}

\section{In vitro evaluations}

Flow cytometric analysis. Flow cytometric analysis revealed varied levels of HER1-expression for the mesothelioma cell lines evaluated (Table S1). NCI-H226 had the highest mean fluorescence intensity (MFI), whereas NCI-H2452 had the lowest MFI (Table S1). Panitumumab and cetuximab demonstrated comparable in vitro binding characteristics for each cell type, as evidenced by the percentage of cells stained with each of the mAb.

Radiochemistry. The ${ }^{86} \mathrm{Y}$ labeled RICs were successfully prepared with radiochemical yields ranging from $60-75 \%$, specific activity exceeding $2 \mathrm{GBq} / \mathrm{mg}$, and with acceptable in vitro receptor-specificity as previously described $[29,30]$.

\section{In vivo evaluations}

Biodistribution studies. In mice bearing the NCI-H226 tumor xenograft, significant decreases in the blood pool activity was observed over a $4 \mathrm{~d}$ time period for both RICs (Table 1). For ${ }^{86}$ Y-CHX-A"-DTPA-panitumumab, the blood \% ID/g decreased from $12.06 \pm 1.28$ at $1 \mathrm{~d}$ to $6.94 \pm 1.09 \% \mathrm{ID} / \mathrm{g}$ at $4 \mathrm{~d}$, a $43 \%$ decrease. ${ }^{86}$ Y-CHX-A"-DTPA-cetuximab showed an even greater decrease beginning with a blood $\% \mathrm{ID} / \mathrm{g}$ of $11.70 \pm 1.44 \% \mathrm{ID} / \mathrm{g}$ at $1 \mathrm{~d}$ and ending with $3.40 \pm 0.60 \% \mathrm{ID} / \mathrm{g}$ at $4 \mathrm{~d}$ injection, $29 \%$ of the initial level. Meanwhile, the tumor uptake increased over a $4 \mathrm{~d}$ time period for both RICs (Table 1). The tumor \%ID/g of ${ }^{86} \mathrm{Y}-$ CHX-A"-DTPA-panitumumab, was $23.13 \pm 3.36$ at $1 \mathrm{~d}$ which increased to $33.18 \pm 1.84$ at $4 \mathrm{~d}$; similarly for ${ }^{86} \mathrm{Y}-\mathrm{CHX}-\mathrm{A}$ "DTPA-cetuximab, the tumor \% ID/g was $21.24 \pm 1.90 \% \mathrm{ID} / \mathrm{g}$ at 1 $\mathrm{d}$ and increased to $28.93 \pm 3.354 \mathrm{~d}$ post-injection. The ${ }^{86} \mathrm{Y}-\mathrm{CHX}-$ A"-DTPA-panitumumab and ${ }^{86}$ Y-CHX-A"-DTPA-cetuximab uptake in all the three tumor models was HER1-mediated as demonstrated by receptor-blocking experiments performed by coinjecting $0.1 \mathrm{mg}$ of the corresponding unlabeled $\mathrm{mAb}$ (Fig. 1). In mice bearing NCI-H226 (Fig. 1A), MSTO-211H (Fig. 1B) or NCI2052 (Fig. 1C) tumors, the tumor $\%$ ID $/ g$ at $3 \mathrm{~d}$ was $36.5 \pm 2.1$, $23.4 \pm 0.9$ and $18.2 \pm 1.8$, respectively, after i.v. injection of ${ }^{86} \mathrm{Y}$ CHX-A"-DTPA-panitumumab. The corresponding tumor \% ID/ $\mathrm{g}$ in mice co-injected with $0.1 \mathrm{mg}$ of panitumumab was $14.1 \pm 1.1$, $12.7 \pm 1.0$ and $8.3 \pm 0.8$, respectively, at the same time point, thus demonstrating specificity of the ${ }^{86} \mathrm{Y}-\mathrm{CHX}-\mathrm{A}$ "-DTPApanitumumab. Similarly, for ${ }^{86}$ Y-CHX-A"-DTPA-cetuximab, the tumor $\% \mathrm{ID} / \mathrm{g}$ at $3 \mathrm{~d}$ was $29.4 \pm 2.5,22.8 \pm 6.2$ and $19.1 \pm 1.9$, respectively, and the corresponding tumor $\%$ ID $/ g$ in mice co-injected with $0.1 \mathrm{mg}$ of cetuximab was $8.2 \pm 0.7,10.0 \pm 2.3$ and $9.2 \pm 0.3$, respectively, at the same time point. The values were significantly different $(p<0.05)$ between unblocked and blocked groups for each tumor type and for both RICs. Although both RICs demonstrated HERl-mediated targeting characteristics, subtle and noteworthy differences in organ uptake were observed at different time points after the injection (Table 1). At 1 and $2 \mathrm{~d}$ after injection, the liver uptake of ${ }^{86} \mathrm{Y}-\mathrm{CHX}-\mathrm{A}$ "-DTPAcetuximab was significantly greater $(p=0.007$ and 0.040 at 1 and 2 $\mathrm{d}$, respectively) than the liver uptake of ${ }^{86}$ Y-CHX-A"-DTPApanitumumab in the same tumor model (Table 1). However, at $4 \mathrm{~d}$ after injection, the blood, spleen, kidney, lung and heart uptake of ${ }^{86}$ Y-CHX-A"-DTPA-panitumumab was significantly greater than the uptake of ${ }^{86} \mathrm{Y}-\mathrm{CHX}-\mathrm{A}$ "-DTPA-cetuximab in those organs in the same tumor model (Table 1). Inter-tumor differences were 
Table 1. Biodistribution of ${ }^{86} \mathrm{Y}-\mathrm{CHX}-\mathrm{A}^{\prime \prime}-\mathrm{DTPA}-$ panitumumab and ${ }^{86} \mathrm{Y}-\mathrm{CHX}-\mathrm{A}^{\prime \prime}-\mathrm{DTPA}-\mathrm{cetuximab}$.

\begin{tabular}{|c|c|c|c|c|c|c|c|c|}
\hline \multirow[t]{2}{*}{ Organs } & \multicolumn{2}{|l|}{$1 \mathrm{~d}$} & \multicolumn{2}{|l|}{$2 \mathrm{~d}$} & \multicolumn{2}{|l|}{$3 d$} & \multicolumn{2}{|l|}{$4 d$} \\
\hline & Panitumumab & Cetuximab & Panitumumab & Cetuximab & Panitumumab & Cetuximab & Panitumumab & Cetuximab \\
\hline Blood & $12.06 \pm 1.26$ & $11.70 \pm 1.44$ & $8.59 \pm 1.62$ & $8.16 \pm 0.88$ & $7.55 \pm 0.92$ & $5.66 \pm 0.99$ & $6.94 \pm 1.09$ & $3.40 \pm 0.60^{\#}$ \\
\hline Tumor & $23.13 \pm 3.36$ & $21.24 \pm 1.90$ & $27.23 \pm 2.18$ & $24.69 \pm 1.99$ & $36.55 \pm 2.04$ & $29.43 \pm 2.53$ & $33.18 \pm 1.84$ & $28.93 \pm 3.35$ \\
\hline Liver & $7.38 \pm 0.83$ & $13.15 \pm 1.21^{\#}$ & $6.64 \pm 0.61$ & $9.53 \pm 0.93^{\#}$ & $6.35 \pm 0.82$ & $8.77 \pm 0.91$ & $5.04 \pm 0.32$ & $5.90 \pm 0.82$ \\
\hline Spleen & $4.69 \pm 1.04$ & $3.96 \pm 0.51$ & $4.75 \pm 0.68$ & $3.80 \pm 0.49$ & $4.05 \pm 0.02$ & $3.58 \pm 0.59$ & $4.22 \pm 0.28$ & $1.48 \pm 0.25^{\#}$ \\
\hline Kidney & $3.45 \pm 0.71$ & $3.61 \pm 0.46$ & $2.58 \pm 0.18$ & $2.55 \pm 0.21$ & $2.69 \pm 0.56$ & $3.06 \pm 0.16$ & $2.35 \pm 0.18$ & $1.53 \pm 0.15^{\#}$ \\
\hline Lungs & $5.96 \pm 1.39$ & $5.12 \pm 0.35$ & $5.03 \pm 2.40$ & $3.08 \pm 0.23$ & $5.67 \pm 0.79$ & $4.25 \pm 0.50$ & $4.45 \pm 0.17$ & $1.92 \pm 0.36^{\#}$ \\
\hline Heart & $3.55 \pm 0.76$ & $3.75 \pm 0.27$ & $2.29 \pm 0.39$ & $1.96 \pm 0.12$ & $2.81 \pm 0.41$ & $2.50 \pm 0.09$ & $2.45 \pm 0.16$ & $1.24 \pm 0.14^{\#}$ \\
\hline Muscle & $1.75 \pm 0.21$ & $1.54 \pm 0.07$ & $1.60 \pm 0.58$ & $1.02 \pm 0.13$ & $1.11 \pm 0.07$ & $1.34 \pm 0.19$ & $1.00 \pm 0.13$ & $0.63 \pm 0.11$ \\
\hline Femur & $2.75 \pm 0.18$ & $3.04 \pm 0.25$ & $2.51 \pm 0.54$ & $2.43 \pm 0.13$ & $2.85 \pm 0.20$ & $2.97 \pm 0.76$ & $2.52 \pm 0.23$ & $2.70 \pm 0.55$ \\
\hline Tail & $2.12 \pm 0.42$ & $2.10 \pm 0.05$ & $1.49 \pm 0.54$ & $2.27 \pm 0.24$ & $1.59 \pm 0.27$ & $2.05 \pm 0.14$ & $2.11 \pm 0.18$ & $1.84 \pm 0.29$ \\
\hline
\end{tabular}

In vivo biodistribution of ${ }^{86} \mathrm{Y}$-CHX-A"-DTPA-panitumumab and ${ }^{86} \mathrm{Y}-\mathrm{CHX}-\mathrm{A}^{\prime \prime}$-DTPA-cetuximab injected i.v. via tail vein of female athymic (NCr) nu/nu mice bearing NCl$\mathrm{H} 226$ tumor xenograft. Biodistribution data were obtained at 1, 2, 3 and $4 \mathrm{~d}$ after injection. All values are expressed as $\%$ ID/g. Data represents the mean value \pm SEM from at least four determinations.

\#Values obtained from ${ }^{86} \mathrm{Y}-\mathrm{CHX}-\mathrm{A}^{\prime \prime}$-DTPA-panitumumab and ${ }^{86} \mathrm{Y}-\mathrm{CHX}-\mathrm{A}^{\prime \prime}$-DTPA-cetuximab were significantly different from each other ( $p<0.05$ ).

doi:10.1371/journal.pone.0018198.t001

observed too. The liver uptake of ${ }^{86}$ Y-CHX-A"-DTPApanitumumab was greater in mice bearing NCI-H226 tumors than in mice bearing MSTO-211H tumors; however, the same phenomenon was not observed with ${ }^{86}$ Y-CHX-A"-DTPAcetuximab (Fig. 2A and B).

PET imaging studies and pharmacokinetic analysis. Small animal PET imaging studies were performed in female athymic mice bearing NCI-H226, MSTO-211H and NGIH2052 tumor xenografts injected with 1.7-1.9 MBq of RIC or RIC co-injected with $0.1 \mathrm{mg}$ excess of the corresponding $\mathrm{mAb}$ (Figure 2). Tumors were clearly visualized in maximum intensity projections of mice imaged from 0.5 to $3 \mathrm{~d}$ after injection of either of the RICs. The tumor-to-background ratios improved over the period primarily due to the decrease and clearance of the radioactivity in blood, liver and background while the tumor uptake increased. In contrast, when $0.1 \mathrm{mg}$ of excess mAb was co-injected with its corresponding RIC, tumors were poorly visualized due to receptor-specific blockage, demonstrating the HER 1-specificity of both radioimmunoconjugates also shown in quantitative information obtained from PET studies (Figure 3). Significant differences were found between the liver uptake of mice injected with ${ }^{86}$ Y-CHX-A"-DTPA-panitumumab and mice injected with ${ }^{86}$ Y-CHX-A"'-DTPA-cetuximab, particularly in the NCI-H226 and MSTO-211H tumor models. The liver clearance of the ${ }^{86} \mathrm{Y}-\mathrm{CHX}-\mathrm{A}$ "-DTPA-cetuximab was slower than that of ${ }^{86}$ Y-CHX-A"-DTPA-panitumumab therefore resulting in lower tumor-liver ratios than ${ }^{86} \mathrm{Y}-\mathrm{CHX}-\mathrm{A}$ "-DTPA-panitumumab.

Pharmacokinetic analyses performed on biodistribution and PET derived values, and from values obtained from serial blood sampling revealed further differences between " ${ }^{86} \mathrm{Y}-\mathrm{CHX}-\mathrm{A}$ "DTPA-panitumumab and ${ }^{86}$ Y-CHX-A"-DTPA-cetuximab (Table 2). The blood $\mathrm{T}_{1 / 2} \alpha$ for ${ }^{86} \mathrm{Y}$-CHX-A"-DTPA-panitumumab was significantly slower than that of ${ }^{86} \mathrm{Y}-\mathrm{CHX}-\mathrm{A}$ "-DTPAcetuximab; however, no significant difference was observed between the two RICs in the $\mathrm{T}_{1 / 2} \beta$ phase. The ${ }^{86} \mathrm{Y}-\mathrm{CHX}-\mathrm{A}$ "DTPA-panitumumab blood $\mathrm{AUC}_{[0 \rightarrow 4]}$ values were slightly greater than ${ }^{86}$ Y-CHX-A"-DTPA-cetuximab values, however the difference was not statistically significant. For both RICs, the tumor $\mathrm{AUC}_{[0 \rightarrow 4]}$ value were highest for mice bearing NCI-H266 tumor xenografts and lowest for mice bearing NCI-H2052 tumor xenografts (Table 2). For each tumor model, the ${ }^{86}$ Y-CHX-A"DTPA-cetuximab liver $\mathrm{AUC}_{[0 \rightarrow 4]}$ values were significantly greater than that of ${ }^{86}$ Y-CHX-A"'-DTPA-panitumumab. The ${ }^{86}$ Y-CHXA"-DTPA-panitumumab tumor $\mathrm{AUC}_{[0 \rightarrow 4]}$ : liver $\mathrm{AUC}_{[0 \rightarrow 4]}$ ratio values were $1.7,2.5$ and 1.4 times greater than values obtained from ${ }^{86}$ Y-CHX-A"-DTPA-cetuximab in mice bearing NCI-H226, MSTO-211H and NCI-H2052, respectively (Table 2). The mean residence times were identical for all of the tumor models and RICs. For both RICs, PET derived tumor $\mathrm{AUC}_{[0 \rightarrow 3]}$ values were significantly greater than corresponding tumor $\mathrm{AUC}_{[0 \rightarrow 3]}$ values derived from blocking experiments with $0.1 \mathrm{mg}$ excess $\mathrm{mAb}$ coinjection (Table 2 and Figure 3), thus again demonstrating HER1mediated tumor accumulation over the $3 \mathrm{~d}$ study period. The organ uptake values quantified by PET were closely related $\left(\mathrm{r}^{2}=0.92, p=0.90, \mathrm{n}=76\right)$ to values determined by ex vivo biodistribution studies.

\section{Discussion}

Information available from the Surveillance, Epidemiology and End Results (SEER) confirms that the incidence of mesothelioma has increased in recent years from almost nil to the current 2500-3000 cases per year in the USA [1]. Diagnosis of $\mathrm{MM}$ is difficult and current treatments do not provide significant improvements in survival. Computed Tomography (CT) has been widely used as the primary imaging modality for the diagnosis, staging, and monitoring of therapeutic response in MM. More recently, MRI and PET imaging with FDG have gained popularity for imaging MM because of the excellent resolution and superiority in the differentiation of malignant from benign disease [32,33,34]. A prospective study comprising 32 patients, 19 with malignant and 13 with benign disease, found that FDG PET had a high negative predictive value of 92\%. FDG PET imaging showed an absence of FDG uptake, and correctly classified $31 / 35$ benign lesions. Nevertheless, the usefulness of FDG is limited by its uptake in inflammatory cells such as macrophages and activated lymphocytes, which can cause false-positive results as seen in cases of parapneumonic effusion, tuberculous and uraemic pleural disease [35,36]. In spite of recent advances in the diagnosis of MM, therapeutic 
A

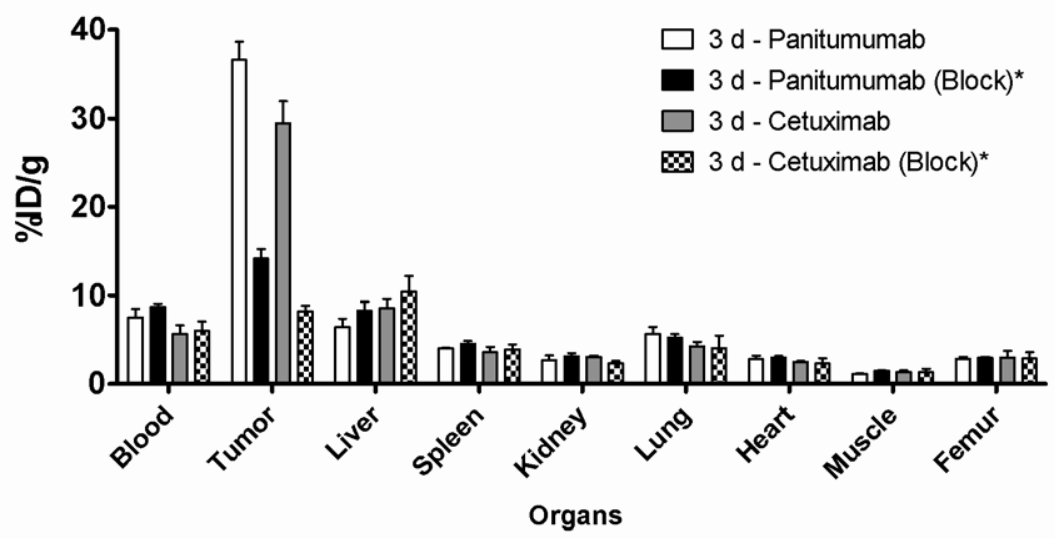

B

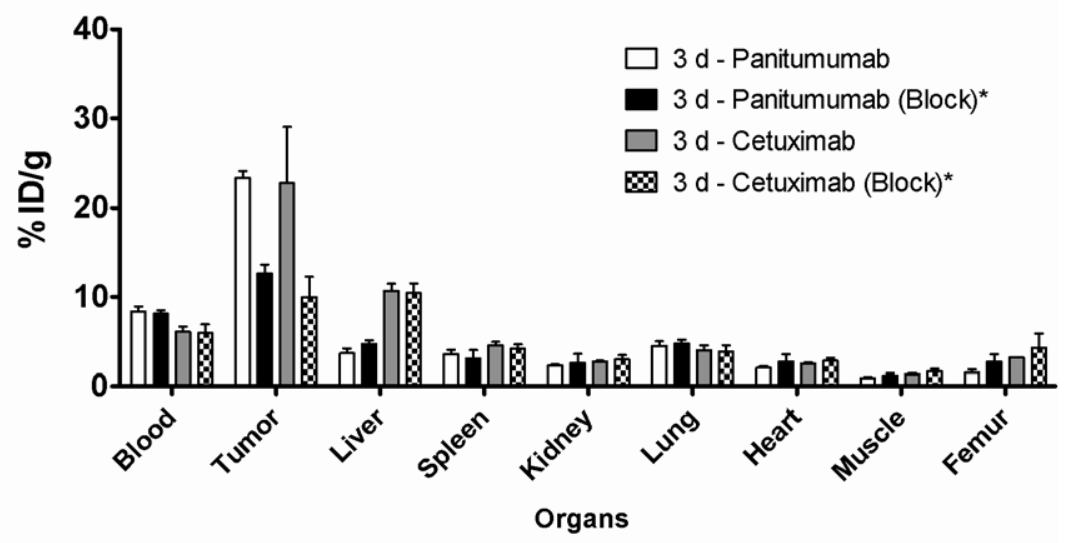

C

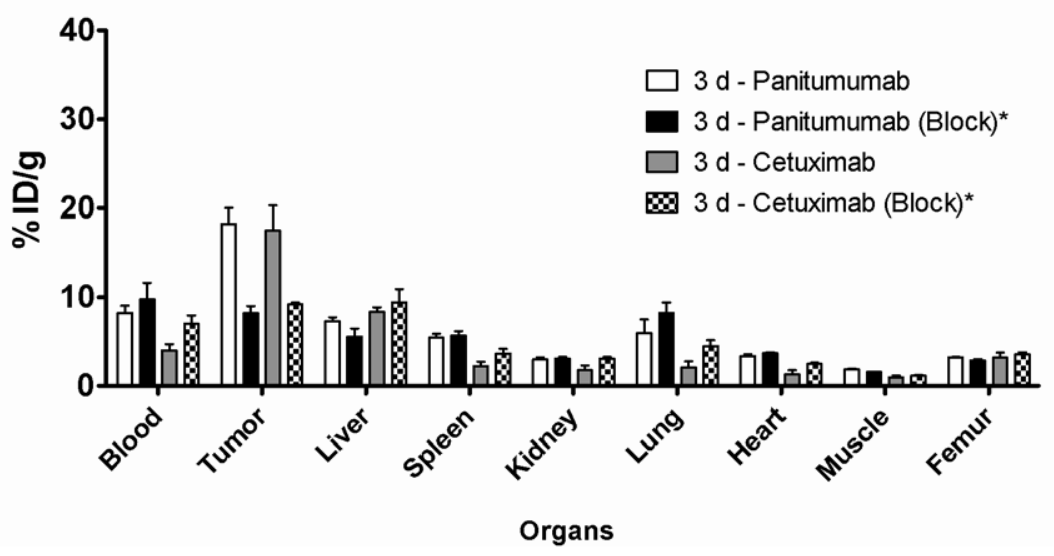

Figure 1. HER1-specificity of ${ }^{86}$ Y-CHX-A"-DTPA-panitumumab and ${ }^{86}$ Y-CHX-A"-DTPA-cetuximab. Receptor-meditated uptake of ${ }^{86}$ YCHX-A"-DTPA-panitumumab and ${ }^{86} \mathrm{Y}-\mathrm{CHX}-\mathrm{A}^{\prime \prime}$-DTPA-cetuximab in selected organs of female athymic ( $\mathrm{NCr}$ ) nu/nu mice bearing NCI-H226 (A), MSTO$211 \mathrm{H}($ B) and $\mathrm{NCl}-\mathrm{H} 2052$ tumor xenografts $($ C). Biodistribution data were obtained $3 \mathrm{~d}$ after injection. All values are expressed as $\%$ ID/g. Data represent the mean value \pm SEM from at least three determinations. * Receptor blocking studies were performed by co-injecting $0.1 \mathrm{mg} \mathrm{mAb}$ with the radiotracer. Values obtained from the blocking studies were significantly lower than the unblocked studies $(p<0.05)$ demonstrating receptormediated accumulation in the tumors.

doi:10.1371/journal.pone.0018198.g001

outcomes have not greatly improved. Surgical resection and adjuvant radiation therapy remain the mainstay of treatment for patients with resectable MM [37].

Occupational exposure to asbestos remains the major risk factor for MM. This exposure has been demonstrated to be associated with increased HERl activation and expression [7,8,9]. There- fore, HER 1-targeted imaging can play a complimentary role in a better understanding of asbestos-induced mesothelioma. While traditional targeting of HER 1 for therapy has not been successful, it is feasible that HER 1 binding molecules could be used as vectors to effectively deliver imageable or cytotoxic radioactive payloads differentially to MM cells to potentially improve diagnostic as well 


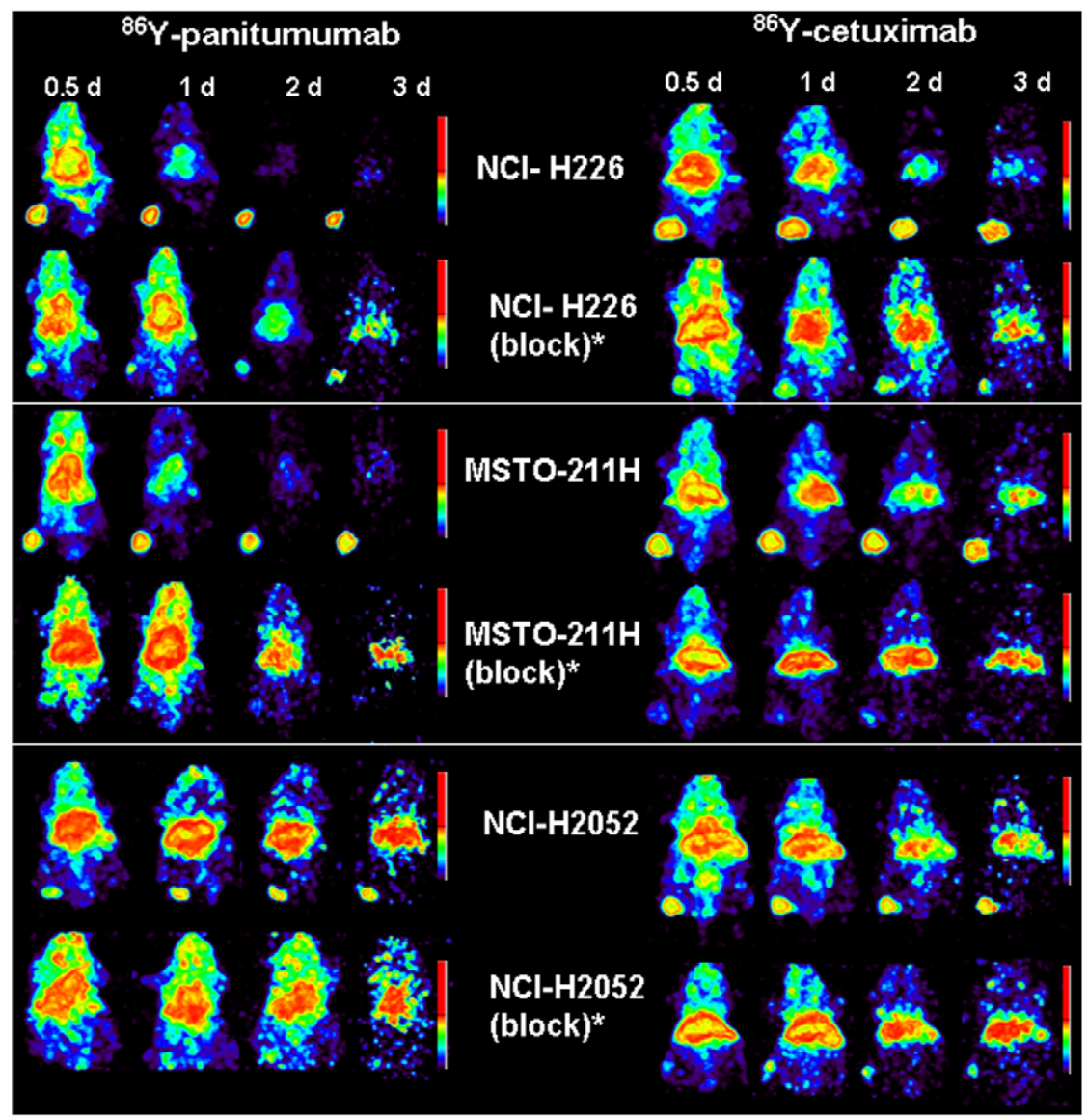

Figure 2. PET imaging of mesothelioma with ${ }^{86} \mathbf{Y}-\mathrm{CHX}-\mathrm{A}^{\prime \prime}-\mathrm{DTPA}$-panitumumab and ${ }^{86} \mathrm{Y}-\mathrm{CHX}-\mathrm{A}^{\prime \prime-D T P A-c e t u x i m a b . ~ R e p r e s e n t a t i v e ~}$ reconstructed and processed maximum intensity projections of female athymic $(\mathrm{NCr}) n u / n u$ mouse bearing $\mathrm{NCl}-226, \mathrm{MSTO}-211 \mathrm{H}$ and $\mathrm{NCl}-\mathrm{H} 2052$ tumor xenografts. Mice represented in the images were injected i.v. via the tail vein with $1.7-1.9 \mathrm{MBq} /<5 \mu \mathrm{g}$ of the radioimmunoconjugate or coinjected with $0.1 \mathrm{mg}$ excess mAb. The scale represents \% maximum and minimum threshold intensity. "Receptor blocking studies were performed by co-injecting $0.1 \mathrm{mg}$ excess $\mathrm{mAb}$ with the corresponding radioimmunoconjugate.

doi:10.1371/journal.pone.0018198.g002

as therapeutic outcomes. Towards this end, the in vivo targeting characteristics of two HER 1-binding monoclonal antibodies, cetuximab and panitumumab, each labeled with ${ }^{86} \mathrm{Y}$, were comparatively evaluated as potential diagnostics by PET imaging, and to select a potential candidate for evaluation in monoclonal antibody targeted RIT applications.

In vitro HER 1 expression was observed in four MM cell lines evaluated (Table S1) similar to the clinical findings of HERl over-expression in majority of MM [10,11,12,13]. HER1specific tumor targeting was observed in all three xenograft tumor models evaluated (Figs. 1, 2, and Table 2) supporting the hypothesis that HER 1 targeting can be used for imaging and radionuclide therapy of MM. Although both radiolabeled cetuximab and panitumumab demonstrated in vivo HER 1targeting characteristics, disparities were observed with blood clearance and non-target organ uptake (Table 1 and 2). Cetuximab is a chimeric $\operatorname{IgG}_{1} \mathrm{mAb}_{\text {, whereas panitumumab is }}$ a fully human $\operatorname{IgG}_{2} \mathrm{mAb}$ and binds to a different epitope of the HER 1 antigen than cetuximab. Antibodies are usually cleared through their interaction with the $\mathrm{F}_{\mathrm{c}}$ receptors expressed on cells of the reticuloendothelial system $[38,39]$. The slower firstphase blood clearance of ${ }^{86} \mathrm{Y}$-CHX-A"-DTPA-panitumumab may be attributed to the fact that panitumumab is an $\mathrm{IgG}_{2}$ whereas cetuximab is an $\operatorname{IgG}_{1}$. $\mathrm{IgG}_{2}$ antibodies have lower

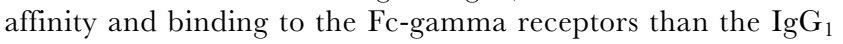

and therefore are cleared more slowly by this mechanism $[38,39]$. As observed in the biodistribution (Table 1) and PET imaging studies (Fig. 2 and Table 2), the liver uptake and accumulation of ${ }^{86}$ Y- CHX-A"-DTPA-cetuximab was significantly greater than that of ${ }^{86} \mathrm{Y}$ - CHX-A"'-DTPA-panitumumab in all three xenograft tumor models, and as a result, tumor to liver ratios were better for ${ }^{86} \mathrm{Y}$ - CHX-A"-DTPA-panitumumab than ${ }^{86}$ Y- CHX-A"-DTPA-cetuximab (Table 2). For ${ }^{90} \mathrm{Y}$ - RIT, the data obtained from this pre-clinical study indicate that RIT with ${ }^{90}$ Y- CHX-A"'DTPA-cetuximab and ${ }^{90}$ Y- CHX-A"'DTPA-panitumumab will result in similar tumor accumulation; however, that same data also suggests that ${ }^{90} \mathrm{Y}-\mathrm{CHX}-\mathrm{A}$ "'DTPA-cetuximab will result in higher radiation doses to the liver than ${ }^{90}$ Y- CHX-A"-DTPA-panitumumab due significantly greater cumulative activity in liver (presented as AUC in table 2). Therefore, ${ }^{90} \mathrm{Y}$ - CHX-A"-DTPA-panitumumab may be a more favorable candidate for RIT than ${ }^{90} \mathrm{Y}-\mathrm{CHX}-\mathrm{A}$ "DTPA-cetuximab due to higher tumor:liver that may result in lower radiation doses to the normal organs than ${ }^{90} \mathrm{Y}-\mathrm{CHX}-\mathrm{A}$ "DTPA-cetuximab. Previous clinical study with ${ }^{111}$ In labeled 225 (murine version of cetuximab) suggests the presence of HER 1 receptor in the liver based on the dose-dependent liver uptake and clearance of the ${ }^{111}$ In labeled murine 225 . However, a study performed with radiolabeled chimeric mAb, C225 (cetuximab) concluded that the residence time in the liver 

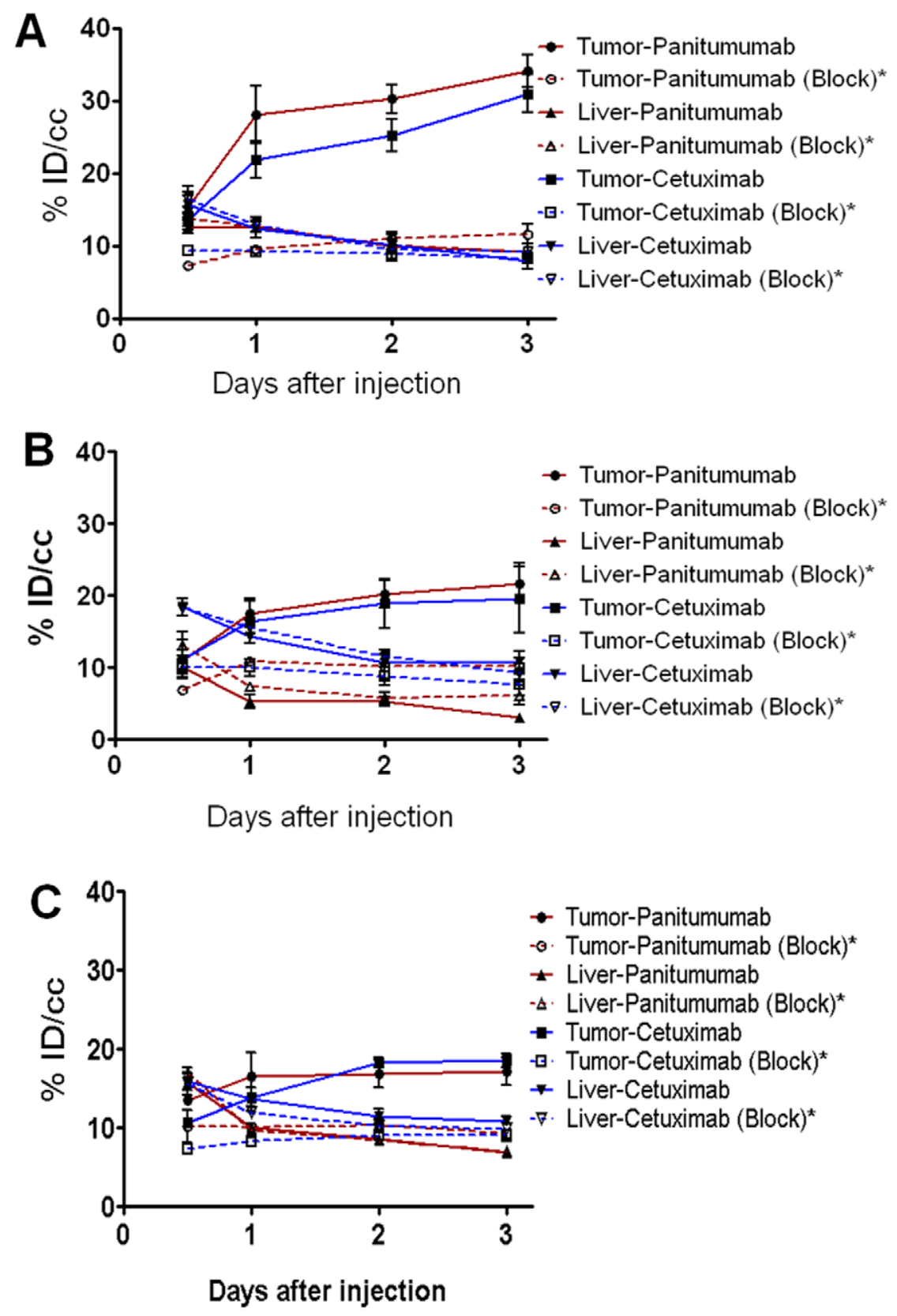

Figure 3. Time-activity curves obtained from quantitative PET imaging of mesothelioma with ${ }^{86} \mathrm{Y}-\mathrm{CHX}$-A"-DTPA-panitumumab and ${ }^{86}$ Y-CHX-A"-DTPA-cetuximab. PET generated time-activity curves in mice bearing (A) NCl-H226, (B) MSTO-211H and (C) NCl-H2052 tumor xenografts. "Receptor blocking studies were performed by co-injecting $0.1 \mathrm{mg}$ excess mAb with the corresponding radioimmunoconjugate. doi:10.1371/journal.pone.0018198.g003

appeared to be longer in patients with cold loading than in those without. One explanation could indeed be that the liver does not have C225 binding sites, but simply metabolically extracts whatever is not taken up elsewhere in the body. In the preclinical study performed in the report, the uptake in liver was not blocked by co-injecting excess cetuximab and panitumumab, suggesting the lack of cetuximab and panitumumab binding sites in mouse liver, which in part concurs with the information provided by the manufacturer of cetuximab, ImClone Systems. Therefore, the differences in liver zzzuptake may be a function of radiometabolities and/or Fc-gamma interactions of cetuximab and panitumumab. These differences can also have a significant impact for targeting intrapleural and intraperitoneal MM with respect to signal to noise ratios as well as radiation doses delivered to the liver, particularly in the setting of radionuclide therapy.

For this reason, panitumumab presents as a better alternative than cetuximab for HER1-targeted imaging and RIT. The HER 1- targeting characteristics of radiolabeled panitumumab shown here points to its potential as a great diagnostic tool for detection and staging of MM. The results also point to the potential of panitumumab as a vehicle for delivering therapeutic radioactivity to HER 1-expressing MM tumors. This approach to MM therapy should improve outcomes for HER 1 over-expressing tumors that have not responded to classical HER 1 therapy with TKIs and monoclonal antibodies due to resistance. 
Table 2. Pharmacokinetic characteristics of ${ }^{86} \mathrm{Y}-\mathrm{CHX}-\mathrm{A}^{\prime \prime}-\mathrm{DTPA}$ panitumumab and ${ }^{86} \mathrm{Y}-\mathrm{CHX}-\mathrm{A}^{\prime \prime}-\mathrm{DTPA}-\mathrm{cetuximab.}$

\begin{tabular}{|c|c|c|c|c|c|c|}
\hline \multirow{2}{*}{$\begin{array}{l}\text { Pharmacokinetic } \\
\text { characteristics } \\
{ }^{86} \text { Y labeled antibody }\end{array}$} & \multicolumn{2}{|l|}{ NCI-H226 } & \multicolumn{2}{|l|}{ MSTO-211H } & \multicolumn{2}{|l|}{ NCI-H2052 } \\
\hline & Panitumumab & Cetuximab & Panitumumab & Cetixumab & Panitumumab & Cetuximab \\
\hline $\begin{array}{l}\text { In vitro expression } \\
\text { as MFI (\%) }\end{array}$ & 375.4 (99.85) & $345.4(99.7)$ & $217.2(87.2)$ & $224.4(79.9)$ & $330.5(93.0)$ & $337.5(90.3)$ \\
\hline Blood clearance (h) & $\begin{array}{l}\alpha-t_{1 / 2}=3.1 \pm 1.4 \\
\beta-t_{1 / 2}=62.1 \pm 16.1\end{array}$ & $\begin{array}{l}\alpha-t_{1 / 2}=0.9 \pm 0.2^{\#} \\
\beta-t_{1 / 2}=43.5 \pm 11.5\end{array}$ & $\begin{array}{l}\alpha-t_{1 / 2}=3.0 \pm 0.9 \\
\beta-t_{1 / 2}=58.1 \pm 10.2\end{array}$ & $\begin{array}{l}\alpha-\mathrm{t}_{1 / 2}=1.1 \pm 0.1^{\#} \\
\beta-\mathrm{t}_{1 / 2}=47.8 \pm 11.9\end{array}$ & $\begin{array}{l}\alpha-t_{1 / 2}=2.6 \pm 1.2 \\
\beta-t_{1 / 2}=86.9 \pm 24.3\end{array}$ & $\begin{array}{l}\alpha-t_{1 / 2}=0.9 \pm 0.3^{\#} \\
\beta-t_{1 / 2}=46.1 \pm 9.8\end{array}$ \\
\hline $\begin{array}{l}\text { Blood AUC }{ }_{[0 \rightarrow 4]} \\
\left.\left(\% \mid I^{\prime} \cdot d^{-1}\right)^{-1}\right)\end{array}$ & $26.6 \pm 1.5$ & $21.7 \pm 2.3$ & $30.3 \pm 2.1$ & $29.7 \pm 1.9$ & $30.3 \pm 1.8$ & $29.7 \pm 3.1$ \\
\hline $\begin{array}{l}\text { Tumor AUC } \\
\left(\% \mid{ }_{[0 \rightarrow 4]} \cdot g^{-1}\right)\end{array}$ & $105.7 \pm 5.8$ & $90.4 \pm 8.2$ & $69.8 \pm 8.5$ & $63.0 \pm 4.2$ & $60.6 \pm 3.4$ & $58.6 \pm 2.9$ \\
\hline $\begin{array}{l}\text { Liver } A^{\prime} C_{[0 \rightarrow 4]} \\
\left(\% \text { ID } d \cdot g^{-1}\right)\end{array}$ & $24.2 \pm 1.2$ & $35.1 \pm 3.2^{\#}$ & $18.2 \pm 1.1$ & $40.6 \pm 3.3^{\#}$ & $29.7 \pm 2.1$ & $40.7 \pm 3.4^{\#}$ \\
\hline 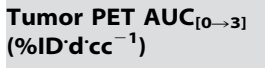 & $72.3 \pm 4.8$ & $60.7 \pm 5.5$ & $46.9 \pm 5.5$ & $43.7 \pm 3.2$ & $41.2 \pm 3.9$ & $40.6 \pm 2.6$ \\
\hline $\begin{array}{l}\text { Tumor PET AUC } \\
\left(\%,{ }_{[0 \rightarrow 3]} d^{\prime} c^{-1}\right)^{*}\end{array}$ & $26.1 \pm 1.2$ & $22.3 \pm 0.4$ & $25.0 \pm 1.2$ & $22.5 \pm 1.0$ & $25.0 \pm 0.9$ & $21.6 \pm 1.1$ \\
\hline $\begin{array}{l}\text { Tumor AUC }[0 \rightarrow 4] \text { : } \\
\text { Blood } A \cup C_{[0 \rightarrow 4]}\end{array}$ & 4.0 & 4.2 & 2.3 & 2.1 & 2.0 & 2.0 \\
\hline 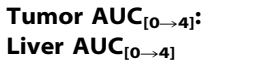 & 4.4 & 2.6 & 3.8 & 1.5 & 2.0 & 1.4 \\
\hline $\begin{array}{l}\text { Tumor AUMC } C_{[0 \rightarrow 4]} \\
\left(\% \text { ID } d^{2} \cdot g^{-1}\right)\end{array}$ & $253.6 \pm 16.2$ & $216.8 \pm 18.4$ & $172.5 \pm 18.1$ & $151.0 \pm 11.2$ & $152.3 \pm 8.1$ & $146.4 \pm 9.9$ \\
\hline Tumor MRT (d) & 2.4 & 2.4 & 2.5 & 2.4 & 2.5 & 2.5 \\
\hline
\end{tabular}

Pharmacokinetic characteristics of ${ }^{86} \mathrm{Y}-\mathrm{CHX}-\mathrm{A}^{\prime \prime}$-DTPA-panitumumab and ${ }^{86} \mathrm{Y}-\mathrm{CHX}-\mathrm{A}^{\prime \prime}$-DTPA-cetuximab injected i.v. via tail vein of female athymic (NCr) nu/nu mice bearing $\mathrm{NCl}-\mathrm{H} 226, \mathrm{MSTO}-211 \mathrm{H}$ and $\mathrm{NCl}-\mathrm{H} 2052$ tumor xenografts. Data represent the mean values from three to six determinations.

* Receptor blocking studies were performed by co-injecting $0.1 \mathrm{mg} \mathrm{mAb}$ with the radiotracer. Values obtained from the blocking studies were significantly lower than the unblocked studies $(p<0.05)$ demonstrating receptor-mediated accumulation in the tumors.

\#Values obtained from ${ }^{86} \mathrm{Y}-\mathrm{CHX}-\mathrm{A}^{\prime \prime}$-DTPA-panitumumab and ${ }^{86} \mathrm{Y}-\mathrm{CHX}-\mathrm{A}^{\prime \prime}$-DTPA-cetuximab were significantly different from each other $(p<0.05)$.

doi:10.1371/journal.pone.0018198.t002

\section{Conclusions}

In this study, the more favorable HERl-targeting characteristics of ${ }^{86} \mathrm{Y}$ - CHX-A"-DTPA-panitumumab than ${ }^{86} \mathrm{Y}$ - CHX-A"DTPA-cetuximab for non-invasive staging and assessment of the HER 1 status of MM has been demonstrated. HER1-targeted immunoPET can be complimentary to CT and MRI for diagnosis and prognosis of MM. Valuable molecular information on further understanding the role of HER 1 in asbestos-induced MM may also be garnered. In conclusion, the strategy to target asbestos-induced HER 1 over-expression for molecular imaging and radionuclide therapy warrants further investigation for clinical translation and improved clinical outcomes and management of MM.

\section{Materials and Methods}

\section{Cell lines and tissue culture}

NCI-H226, NCI-H2052, NCI-H2452 and MSTO-211H human mesothelioma cells were purchased from American Type Culture Collection (Manassas, VA). All cell lines were grown as a monolayer at $37^{\circ} \mathrm{C}$, in a humidified atmosphere of $5 \% \mathrm{CO}_{2}$ and $95 \%$ air. Cells were cultured in RPMI-1640 media containing $2 \mathrm{mM} \mathrm{L}$-glutamine, $10 \mathrm{mM}$ HEPES, $1 \mathrm{mM}$ sodium pyruvate, $4.5 \mathrm{~g} / \mathrm{L}$ glucose, and $1.5 \mathrm{~g} / \mathrm{L}$ sodium bicarbonate. All media were additionally supplemented with $10 \%$ FetalPlex (Gemini Bio-Products, Inc, Woodland, CA, USA). Media and supplements were obtained from Invitrogen (Carlsbad, CA, USA) and Lonza (Walkersville, MD, USA).

\section{Flow-Cytometric Analysis}

HER 1 expression of the mesothelioma cell lines was evaluated by standard flow-cytometric techniques [40]. Briefly, cells were trypsinized, pelleted at $1,500 \times \mathrm{g}$ for $10 \mathrm{~min}$ and re-suspended in phosphate-buffered saline (PBS; pH 7.2) containing 1\% bovine serum albumin (BSA). The cells $\left(1 \times 10^{6}\right.$ cells in $100 \mu \mathrm{L}$ of $1 \%$ BSA in PBS) were added to $12 \times 75 \mathrm{mM}$ polypropylene tubes (Falcon Labware, Franklin Lakes, NJ) along with $1 \mu \mathrm{g}$ of cetuximab (Erbitux: Bristol-Meyers Squibb Co, Princeton, NJ) or panitumumab (Vectibix: Amgen, Thousand Oaks, CA) in $100 \mu \mathrm{L}$. The cells were incubated for $1 \mathrm{~h}$ at $4^{\circ} \mathrm{C}$, washed three times by adding $2 \mathrm{~mL}$ of $1 \% \mathrm{BSA}$ in PBS, pelleting the cells at $1,000 \times \mathrm{g}$ for $5 \mathrm{~min}$ and decanting the supernatant. Following the last wash, $100 \mu \mathrm{L}$ of FITC-labeled goat anti-human IgG $(50 \mu \mathrm{g} / \mathrm{mL}$; Kirkegaard and Perry, Gaithersburg, MD) was added to the cells and incubated for an additional $1 \mathrm{~h}$ at $4^{\circ} \mathrm{C}$. The cells were washed three times as before and analyzed (10,000 events) using a FACScalibur (BD Biosciences, San Jose, CA) with CellQuest software. HuM195, an anti-CD33 mAb kindly provided by Dr. Michael McDevitt at Memorial Sloan-Kettering Cancer Center, served as a control mAb.

\section{Preparation of radioimmunoconjugates}

The ${ }^{86} \mathrm{Y}$ was produced by the previously described ${ }^{86} \mathrm{Sr}(\mathrm{p}, \mathrm{n}){ }^{86} \mathrm{Y}$ reaction using a $\mathrm{SrCO}_{3}$ target [29,41]. The preparation and quality control of ${ }^{86} \mathrm{Y}$-CHX-A"-DTPA-panitumumab and ${ }^{86} \mathrm{Y}$ CHX-A"-DTPA-cetuximab conjugates was performed as previously described $[29,30]$.

\section{Animal and tumor models}

All animal studies were performed in accordance with the NIH guidelines for the humane use of animals and all procedures were reviewed and approved by the National Cancer Institute Animal 
Care and Use Committee (Protocol ID: ROB-104/5). Groups of 5-8 week old female athymic nu/nu mice (Charles River Laboratory, Wilmington, DE) were injected subcutaneously with $2-4 \times 10^{6}$ MSTO-211H, 6- $10 \times 10^{6}$ NCI-H226, or $6-10 \times 10^{6}$ NGI-H2052 cells in $200 \mu \mathrm{L}$ medium containing $20 \%$ matrigel.

\section{Biodistribution and pharmacokinetic studies}

Tumor bearing female athymic mice were intravenously (i.v.) injected with $0.4-0.6 \mathrm{MBq}(<5 \mu \mathrm{g})$ of ${ }^{86} \mathrm{Y}-\mathrm{CHX}-\mathrm{A}$ "-DTPAcetuximab or ${ }^{86}$ Y-CHX-A"-DTPA-panitumumab. To demonstrate HER 1-specificity, excess $\mathrm{mAb}(0.1 \mathrm{mg})$ was co-injected with the corresponding radioimmunoconjugate (RIC) into an additional set of mice bearing each of the tumor xenografts. At the desired time points, the animals were sacrificed by $\mathrm{CO}_{2}$ inhalation. Tumor, blood and selected organs were harvested, wet-weighed, and the radioactivity measured in a Wizard 1480 gamma counter (PerkinElmer, Shelton, CT). The percent injected dose per gram (\% ID/g) of tissue was calculated by comparison with standards representing $10 \%$ of the injected dose per animal. Noncompartmental pharmacokinetics was performed to determine area under the curve (AUC), area under the first moment curve (AUMC) and the mean residence time (MRT) using trapezoidal integration analysis [42]. The sample size for biodistribution study was equal to or greater than four animals per group.

\section{PET imaging studies}

Small animal PET studies were performed using the ATLAS (Advanced Technology Laboratory Animal Scanner) at the National Institutes of Health, Bethesda, MD, USA. Whole body imaging studies ( 6 bed positions, total acquisition time of $1 \mathrm{~h}$ per mouse) were carried out on mice anesthetized with $1.5-1.7 \%$ isoflurane on a temperature-controlled bed as previously described

\section{References}

1. Yang H, Testa JR, Carbone M (2008) Mesothelioma epidemiology, carcinogenesis, and pathogenesis. Curr Treat Options Oncol 9: 147-157.

2. Kamp DW (2009) Asbestos-induced lung diseases: an update. Transl Res 153: $143-152$.

3. Robinson BW, Musk AW, Lake RA (2005) Malignant mesothelioma. Lancet 366: 397-408.

4. Vogelzang NJ, Porta C, Mutti L (2005) New agents in the management of advanced mesothelioma. Semin Oncol 32: 336-350.

5. Robinson BW, Lake RA (2005) Advances in malignant mesothelioma. N Engl J Med 353: 1591-1603.

6. Lee AY, Raz DJ, He B, Jablons DM (2007) Update on the molecular biology of malignant mesothelioma. Cancer 109: 1454-1461.

7. Pache JC, Janssen YM, Walsh ES, Quinlan TR, Zanella CL, et al. (1998) Increased epidermal growth factor-receptor protein in a human mesothelial cell line in response to long asbestos fibers. Am J Pathol 152: 333-340.

8. Zanella CL, Posada J, Tritton TR, Mossman BT (1996) Asbestos causes stimulation of the extracellular signal-regulated kinase 1 mitogen-activated protein kinase cascade after phosphorylation of the epidermal growth factor receptor. Cancer Res 56: 5334-5338.

9. Faux SP, Houghton CE, Hubbard A, Patrick G (2000) Increased expression of epidermal growth factor receptor in rat pleural mesothelial cells correlates with carcinogenicity of mineral fibres. Carcinogenesis 21: 2275-2280.

10. Gaafar R, Bahnassy A, Abdelsalam I, Kamel MM, Helal A, et al. (2010) Tissue and serum EGFR as prognostic factors in malignant pleural mesothelioma. Lung Cancer 70: 43-50.

11. Kothmaier H, Quehenberger F, Halbwedl I, Morbini P, Demirag F, et al. (2007) EGFR And PDGFR Differentially Promote Growth In Malignant Epitheloid Mesothelioma Of Short- And Long-term Survivors. Thorax.

12. Edwards JG, Swinson DE, Jones JL, Waller DA, O'Byrne KJ (2006) EGFR expression: associations with outcome and clinicopathological variables in malignant pleural mesothelioma. Lung Cancer 54: 399-407.

13. Okuda K, Sasaki H, Kawano O, Yukiue H, Yokoyama T, et al. (2008) Epidermal growth factor receptor gene mutation, amplification and protein expression in malignant pleural mesothelioma. J Cancer Res Clin Oncol 134: 1105-1111.

14. Destro A, Ceresoli GL, Falleni M, Zucali PA, Morenghi E, et al. (2006) EGFR overexpression in malignant pleural mesothelioma. An immunohistochemical
[29]. Tumor bearing female athymic mice were injected i.v. with 1.7-1.9 MBq $(<5 \mu \mathrm{g})$ of ${ }^{86} \mathrm{Y}$-CHX-A"-DTPA-cetuximab or ${ }^{86} \mathrm{Y}$ CHX-A"-DTPA-panitumumab. To determine HER1-specificity, excess unmodified $\mathrm{mAb}(0.1 \mathrm{mg})$ was co-injected with the corresponding RIC. Phantom studies, image acquisition, processing and analysis was performed as previously described [29]. After imaging, the mice were euthanized and biodistribution studies were performed to determine the correlation between PETassessed in vivo \% ID $/ \mathrm{cm}^{3}$ and biodistribution determined ex vivo \% ID/g. The sample size for PET imaging study was equal to or greater than three animals per group.

\section{Statistical Analysis}

All numerical data were expressed as the mean of the values \pm the standard error of mean (SEM). Graphpad Prism version 5 (San Diego, CA, USA) was used for statistical analysis. A $p$ value less than 0.05 was considered statistically significant.

\section{Supporting Information}

Table S1 Relative in vitro expression of HER 1 in human mesothelioma cells determined by FACS based assay. MFI = mean fluorescence intensity.

(DOG)

\section{Author Contributions}

Conceived and designed the experiments: TKN DEM MWB. Performed the experiments: TKN KG KEB DEM. Analyzed the data: TKN DEM. Contributed reagents/materials/analysis tools: TKN DEM KG KEB. Wrote the paper: TKN. and molecular study with clinico-pathological correlations. Lung Cancer 51: 207-215.

15. Garland LL, Rankin C, Gandara DR, Rivkin SE, Scott KM, et al. (2007) Phase II study of erlotinib in patients with malignant pleural mesothelioma: a Southwest Oncology Group Study. J Clin Oncol 25: 2406-2413.

16. Govindan R, Kratzke RA, Herndon JE, 2nd, Niehans GA, Vollmer R, et al. (2005) Gefitinib in patients with malignant mesothelioma: a phase II study by the Cancer and Leukemia Group B. Clin Cancer Res 11: 2300-2304.

17. Boswell CA, Brechbiel MW (2007) Development of radioimmunotherapeutic and diagnostic antibodies: an inside-out view. Nucl Med Biol 34: 757-778.

18. Sharkey RM, Goldenberg DM (2005) Perspectives on cancer therapy with radiolabeled monoclonal antibodies. J Nucl Med 46(Suppl 1): 115S-127S.

19. Zinzani PL, Rossi G, Franceschetti S, Botto B, Di Rocco A, et al. (2010) Phase II trial of short-course R-CHOP followed by 90Y-ibritumomab tiuxetan in previously untreated high-risk elderly diffuse large B-cell lymphoma patients. Clin Cancer Res 16: 3998-4004.

20. Richman CM, DeNardo SJ (2001) Systemic radiotherapy in metastatic breast cancer using 90Y-linked monoclonal MUC-1 antibodies. Crit Rev Oncol Hematol 38: 25-35.

21. Wong JY, Chu DZ, Williams LE, Liu A, Zhan J, et al. (2006) A phase I trial of (90)Y-DOTA-anti-CEA chimeric T84.66 (cT84.66) radioimmunotherapy in patients with metastatic CEA-producing malignancies. Cancer Biother Radiopharm 21: 88-100.

22. Verel I, Visser GW, Boellaard R, Boerman OC, van Eerd J, et al. (2003) Quantitative 89Zr immuno-PET for in vivo scouting of 90Y-labeled monoclonal antibodies in xenograft-bearing nude mice. J Nucl Med 44: 1663-1670.

23. Lovqvist A, Humm JL, Sheikh A, Finn RD, KoziorowskiJ, et al. (2001) PET imaging of (86)Y-labeled anti-Lewis Y monoclonal antibodies in a nude mouse model: comparison between (86)Y and (111)In radiolabels. J Nucl Med 42: 12811287.

24. Helisch A, Forster GJ, Reber H, Buchholz HG, Arnold R, et al. (2004) Pretherapeutic dosimetry and biodistribution of 86Y-DOTA-Phe1-Tyr3-octreotide versus 111 In-pentetreotide in patients with advanced neuroendocrine tumours. Eur J Nucl Med Mol Imaging 31: 1386-1392.

25. Nayak TK, Garmestani K, Baidoo KE, Milenic DE, Brechbiel MW (2011) PET imaging of tumor angiogenesis in mice with VEGF-A-targeted (86)Y-CHX-A"DTPA-bevacizumab. Int J Cancer 128: 920-926. 
26. Philpott GW, Schwarz SW, Anderson CJ, Dehdashti F, Connett JM, et al. (1995) RadioimmunoPET: detection of colorectal carcinoma with positronemitting copper-64-labeled monoclonal antibody. J Nucl Med 36: 1818-1824.

27. Cutler PD, Schwarz SW, Anderson CJ, Connett JM, Welch MJ, et al. (1995) Dosimetry of copper-64-labeled monoclonal antibody $1 \mathrm{~A} 3$ as determined by PET imaging of the torso. J Nucl Med 36: 2363-2371.

28. Milenic DE, Garmestani K, Brady ED, Albert PS, Abdulla A, et al. (2007) Potentiation of high-LET radiation by gemcitabine: targeting HER2 with trastuzumab to treat disseminated peritoneal disease. Clin Cancer Res 13: 1926-1935.

29. Nayak TK, Garmestani K, Baidoo KE, Milenic DE, Brechbiel MW. Preparation, biological evaluation, and pharmacokinetics of the human antiHER 1 monoclonal antibody panitumumab labeled with $86 \mathrm{Y}$ for quantitative PET of carcinoma. J Nucl Med 51: 942-950.

30. Nayak TK, Regino CA, Wong KJ, Milenic DE, Garmestani K, et al. PET imaging of HER1-expressing xenografts in mice with 86Y-CHX-A"-DTPAcetuximab. Eur J Nucl Med Mol Imaging 37: 1368-1376.

31. Behr TM, Behe M, Stabin MG, Wehrmann E, Apostolidis C, et al. (1999) Highlinear energy transfer (LET) alpha versus low-LET beta emitters in radioimmunotherapy of solid tumors: therapeutic efficacy and dose-limiting toxicity of 213Bi- versus 90Y-labeled CO17-1A Fab' fragments in a human colonic cancer model. Cancer Res 59: 2635-2643.

32. Heelan RT, Rusch VW, Begg CB, Panicek DM, Caravelli JF, et al. (1999) Staging of malignant pleural mesothelioma: comparison of CT and MR imaging. AJR Am J Roentgenol 172: 1039-1047.
33. Lee HY, Hyun SH, Lee KS, Kim BT, Kim J, et al. Volume-Based Parameter of (18)F-FDG PET/CT in Malignant Pleural Mesothelioma Prediction of Therapeutic Response and Prognostic Implications. Ann Surg Oncol.

34. Nowak AK, Francis RJ, Phillips MJ, Millward MJ, van der Schaaf AA, et al. (2010) A novel prognostic model for malignant mesothelioma incorporating quantitative FDGPET imaging with clinical parameters. Clin Cancer Res 16: 2409-2417.

35. Benamore RE, O'Doherty MJ, Entwisle JJ (2005) Use of imaging in the management of malignant pleural mesothelioma. Clin Radiol 60: 1237-1247.

36. Kramer H, Pieterman RM, Slebos DJ, Timens W, Vaalburg W, et al. (2004) PET for the evaluation of pleural thickening observed on CT. J Nucl Med 45: 995-998.

37. Tsao AS, Wistuba I, Roth JA, Kindler HL (2009) Malignant pleural mesothelioma. J Clin Oncol 27: 2081-2090.

38. Lobo ED, Hansen RJ, Balthasar JP (2004) Antibody pharmacokinetics and pharmacodynamics. J Pharm Sci 93: 2645-2668.

39. Wang W, Wang EQ, Balthasar JP (2008) Monoclonal antibody pharmacokinetics and pharmacodynamics. Clin Pharmacol Ther 84: 548-558.

40. Milenic DE, Garmestani K, Brady ED, Albert PS, Ma D, et al. (2004) Targeting of HER2 antigen for the treatment of disseminated peritoneal disease. Clin Cancer Res 10: 7834-7841.

41. Garmestani K, Milenic DE, Plascjak PS, Brechbiel MW (2002) A new and convenient method for purification of $86 \mathrm{Y}$ using a $\mathrm{Sr}(\mathrm{II})$ selective resin and comparison of biodistribution of $86 \mathrm{Y}$ and $111 \mathrm{In}$ labeled Herceptin. Nucl Med Biol 29: 599-606.

42. Gibaldi M, Perrier D (1982) Pharmacokinetics. New York: Dekker. viii, 494. 